\title{
El cuerpo, un universo de significados: la instrumentalización corporal en la web y la descorporeización en la escuela
}

\author{
María Victoria Reales Moreno ${ }^{1}$ \\ María Cristina Gamboa Mora ${ }^{2}$
}

Recibido: 08-04-2020

Aceptado: 06-05-2020

\section{Resumen}

El cuerpo ha sido desvirtuado e instrumentalizado en la escuela; este fenómeno social se ha acrecentado de manera "invisible" y ha tomado fuerza durante las últimas décadas tras el dominio de las nuevas tecnologías. La influencia de la web en la reproducción de las prácticas corporales de los jóvenes ha determinado una nueva lectura de la educación. Para nadie es un secreto que las nuevas generaciones aprenden más desde su interacción con las nuevas tecnologías que desde el aula tradicional. Sin embargo, el acceso ilimitado a diversas experiencias virtuales ha desencadenado un fenómeno relativo al concepto corporal que será el interés central de esta investigación, la cual se encuentra en la fase inicial y tiene por objetivo evidenciar los mecanismos utilizados por la web que inciden en la construcción de un nuevo concepto de cuerpo en los jóvenes y la movilización de una nueva idea de corporalidad en la escuela.

\footnotetext{
1. Docente Secretaría de Educación SED Bogotá. Licenciada en Lingüística y Literatura. Universidad Distrital. Magister en Lingüística Uptc. Estudiante Doctorado en Educación Universidad de Baja California México.

Correo electrónico: vickycilla10@yahoo.es

ORCID: https://orcid.org/0000-0001-5026-4651

2. Docente asociada, Escuela de Ciencias de la Educación, Universidad Nacional Abierta y a Distancia, Bogotá, Colombia. Líder del Grupo de Investigación Ambientes de Enseñanza-Aprendizaje de las Ciencias Básicas y Sociales (Ameci).

Correo electrónico: maria.gamboa@unad.edu.co

ORCID: https://orcid.org/0000-0001-8459-099X

Google Scholar: https://scholar.google.es/citations?user=_180qYcAAAAJ\&hl=es
} 
La investigación es de tipo exploratoria y descriptiva; se implementó el análisis de contenido y la hermenéutica, que permiten la interpretación del fenómeno. Se presentará el resultado de la primera fase de la investigación referida a la caracterización del fenómeno, la cual deja como conclusión más relevante hasta el momento la evidencia de la instrumentalización de la dimensión corporal que ha sido establecida en gran parte con la inmersión de las nuevas tecnologías y cómo estas han transformado el concepto corporal en la escuela, influyendo así en los procesos de enseñanza y aprendizaje.

Palabras clave: cuerpo, web, descorporeización, educación, cultura.

\section{The body, a universe of meanings: corporal instrumentalization on the web and disembodiment at school}

\section{Abstract}

The body has been distorted and instrumentalized at school; This social phenomenon has grown in an "invisible" way and has gained strength in recent decades after the mastery of new technologies. The influence of the web on the reproduction of the bodily practices of young people has determined a new reading of education. It is no secret to anyone that new generations learn more from their interaction with new technologies than from the traditional classroom. However, unlimited access to various virtual experiences has triggered a phenomenon related to the body concept that will be the central interest of this research, which is in the initial phase and aims to demonstrate the mechanisms used by the web that affect the construction of a new concept of body in young people and the mobilization of a new idea of corporality in school. 
The research is exploratory and descriptive; content analysis and hermeneutics were implemented, which allow the interpretation of the phenomenon. The result of the first phase of the investigation related to the characterization of the phenomenon will be presented, which leaves as the most relevant conclusion so far the evidence of the instrumentalization of the body dimension that has been established largely with the immersion of new technologies and how these have transformed the body concept at school, thus influencing the teaching and learning processes.

Keywords: body, web, disembodiment, education, culture.

"El cuerpo es el lugar y el tiempo en el que el mundo se hace humano"

David Le Breton

\section{Introducción}

La presente investigación indaga y reflexiona sobre la construcción del papel del cuerpo en la escuela. Más allá de lo biológico y de la dimensión orgánica y material, más allá de la lectura del cuerpo desde lo estético, lo plástico o lo físico, esta investigación se preocupa por pensar el cuerpo en relación con los nuevos discursos hegemónicos, su incidencia en los procesos de enseñanzaaprendizaje, en la formación de los sujetos, y en la construcción de mundo y sociedad desde la misma corporalidad. Esta reflexión parte de considerar el cuerpo como el elemento receptor de la desintegración social y, a su vez, el elemento integrador en la escuela. Al respecto, Jara (1998) plantea que el cuerpo debe ser visto como centro de gravedad, constituido por elementos fisiológicos, teóricos, morales y valorativos, que permiten al ser humano la posibilidad de afirmarse a sí mismo como un individuo perteneciente a la sociedad. 
Pese a esta percepción holística del cuerpo, la investigación se ha preguntado sobre el papel de la escuela en la construcción de los discursos corporales. Al respecto, se ha evidenciado que, cronológicamente, la escuela tradicional se ha pensado como proyecto fragmentario: inicialmente desde el plano civilizador y nacionalizador, posteriormente desde un plano religioso, para llegar finalmente a una concepción científica y moderna desde un carácter logocéntrico. Esta última visión ha permanecido vigente durante varias décadas e intenta dar respuesta a las políticas educativas que privilegian, por un lado, mantener la educación como un derecho social y por el otro, señalar los estándares de calidad para generar procesos de transformación en el recurso humano. Otros proponen la escuela como la herramienta que permite el desarrollo social.

Al respecto, Munévar (2017, citado por Pérez, 2018) considera que "la escuela ha garantizado mano de obra calificada para las empresas y de esta forma se establece el crecimiento económico para un país" (p. 5). Bajo esta perspectiva, se evidencia que el interés dado al cuerpo en la enseñanza en cada una de estas etapas ha sido prescrito, y de manera indirecta se ha reducido a lo higiénico, lo biológico y el disciplinamiento de los mismos mediante técnicas militares que han sido apropiadas por la escuela.

Por su parte, las ciencias sociales han sido el campo que se ha preocupado en los últimos años por los estudios corporales, revelando nuevas formas para entender la construcción sociocultural de los sujetos en la modernidad y el impacto de estas nuevas construcciones sociales en la escuela. Las nuevas formas tecnológicas, la incidencia de los nuevos discursos corporales, la huella de la violencia física y simbólica, entre otros elementos, confluyen en las nuevas narrativas que han sido apropiadas y grabadas en los cuerpos de los jóvenes y que no pueden ser ajenos a los procesos de enseñanza-aprendizaje.

En respuesta a estas situaciones de conflicto, surgen los nuevos discursos sociales enmarcados en la búsqueda de la paz. Estos traen inmersa una serie de acciones pedagógicas que deben "trascender" en la escuela. Sin embargo, el problema es más grande de lo que se 
piensa pues la génesis del conflicto se encuentra también en todo acto de agresión física o simbólica que se ha ido naturalizando con el tiempo en la sociedad.

Al respecto, la Ley 1732 establece la Cátedra de la Paz como de obligatorio cumplimiento en las instituciones educativas del país, cuyo objetivo principal es reconstruir el tejido social. Sin embargo, pese a todos los esfuerzos ahondados en materia de políticas educativas que pretenden resolver de manera legal las rupturas sociales, hay elementos invisibles a los ojos de las normas. Se trata de aquellos discursos corporales hegemónicos, dominantes, sui generis, movilizados a través de las nuevas tecnologías, que han sido apropiados y encarnados por los jóvenes, y que no reconstruyen el tejido social sino que por el contrario se convierten en foco de agresión y violencia simbólica.

A razón de lo anterior la formación humana desde la corporalidad se ha transformado en el talón de Aquiles de las sociedades contemporáneas. El sujeto se ha desentendido y se ha convertido en el caldo de cultivo de una paradoja escolar. Vivimos en un mundo insensible y deshumanizado en el que la escuela no hace mella para preparar a las nuevas generaciones de manera contundente en el rescate de sí mismos y de su sensibilidad. Cada día abundan en la sociedad hechos violentos, descarnados, que atentan contra el otro o contra sí, y la sociedad adopta una participación pasiva e insensible, convirtiéndose en espectadora de la destrucción y la vulneración de los derechos.

En este escenario, juega un papel fundamental el esquema familiar de los jóvenes. Este ha afrontado un cambio drástico en las últimas décadas, sintetizado en la pérdida de la estructura familiar; esto, a su vez, trae consigo el deterioro en la formación humana, afectando el proceso de escolarización de los estudiantes. Por otro lado, pese a los pocos esfuerzos por entender el cuerpo de los jovenes, y pese a la necesidad de los jóvenes por un espacio dado desde lo sensible, lo vivencial y lo experimental, estos han sido conducidos en su formación por sus nuevos maestros y padres inorgánicos, virtuales, encontrados en "la Internet". 
En un principio, la familia era la encargada de la formación. Sin embargo, su rol social se ha desvirtuado y su naturaleza como primera institución encargada de esta actividad se ha transformado, entregando toda la responsabilidad de formación, por un lado a la escuela y, por otro lado, a la familia virtual: "la Internet". La primera asume los nuevos núcleos familiares y facilita la inmersión y aceptación del individuo en sociedad de manera controlada y regulada, pero la segunda, carece de vigilancia y está presente en la cotidianidad de los estudiantes, adoptando el papel camaleónico de padres, amigos, escuela, maestros, pareja entre otros roles. Al respecto, los cuerpos y las subjetividades parecen moldearse a partir de los medios masivos y el consumo, siendo esos los ámbitos donde se plantean los modelos a seguir (Lipovetsky, 1986).

Por otro lado, la racionalización instrumental del cuerpo y el movimiento se ha pensado para adecuarse a las formas de trabajo resultado de la industrialización, siendo la escuela el lugar de entrenamiento perfecto para estas formas corporales. Ello contrasta con las nuevas tecnologías, que están ganando la partida al determinar las formas de interacción social de los sujetos y la construcción de discursos corpóreos y no corpóreos al interior de las aulas.

Frente a este fenómeno social, se parte de reconocer que el sujeto es cuerpo y por tal interactúa y se instaura en el mundo a través de él. De esta manera, se reconoce la importancia del estudio del cuerpo no solo en la formación de sujetos que presentan una huella social impresa, sino también en la formación de ciudadanos capaces de recuperar el tejido social. Para esto, es necesario entender cuál ha sido el reconocimiento y el papel dado en la escuela al cuerpo dentro de su proceso de enseñanza-aprendizaje, como unidad de acercamiento y construcción social, y como dispositivo generador y articulador de conocimientos.

El problema abordado en la investigación refiere a la indagación de 1) cuál es el concepto de cuerpo movilizado en la web, 2) cuál es la construcción simbólica-social creada del mismo en el entorno escolar a partir de los discursos culturales juveniles movilizados y dominantes en la virtualidad y 3) cómo por medio de esta construc- 
ción simbólica se puede analizar la manera en que los docentes y la escuela asumen el cuerpo de los estudiantes. Con esto, se busca plantear posteriormente una estrategia pedagógica que recupere el cuerpo en el aula, no como instrumento que acompaña al sujeto en su proceso de aprendizaje, sino como el dispositivo que hace parte fundamental del proceso efectivo de enseñanza-aprendizaje.

Para esto, se planteó como objetivo general de la investigación en curso la implementación de una propuesta pedagógica, desde el fenómeno de la descorporeización en el aula (cuerpo-objeto), que permita la resignificación del cuerpo simbólico como eje articulador de aprendizajes significativos. De igual manera, los objetivos específicos planteados en la macro investigación fueron:

1. Caracterizar el fenómeno de la instrumentalización corporal en la web, identificando las estrategias discursivas que influyen en la descorporeización en la escuela, haciendo uso de la teoría de la multimodalidad.

2. Elaborar un estudio diacrónico de la relación cuerpoaprendizaje en la educación en Colombia mediante un análisis de contenido.

3. Diseñar una propuesta pedagógica integradora y articuladora que permita la recuperación del cuerpo simbólico de los estudiantes desde el aprendizaje significativo.

En esta oportunidad se presenta el avance de la investigación relacionada con el resultado del primer objetivo general planteado: la caracterización del fenómeno de la descorporeización. 


\section{Referentes teóricos}

La escuela ha abordado el cuerpo desde diferentes perspectivas, por ejemplo, desde las didácticas de la educación física basándose en "el modelo, la instrucción, la estrategia y el desarrollo de las habilidades que acentúan el disciplinamiento y la normalización, se han creado cuerpos domesticados, corregidos, controlados, adiestrados y desarrollados" (Bassani, Fensterseifer y Silva, p. 200, 2011, citado por Gallo, 2017, p.200). También se ha entendido el cuerpo como objeto y blanco de poder, en términos de Foucault (2001), o como artefacto capaz de articular las prácticas comunicativas, los movimientos sociales, las diferentes temporalidades y la pluralidad de matices culturales (Martín-Barbero, 1987).

El cuerpo es un eje receptor de la problemática social, un universo significativo que se encuentra escondido, violentado, olvidado y subvalorado. En la escuela, a lo largo de la historia se han privilegiado los procesos mentales y se ha resumido la dimensión corporal a disciplinas centradas en el campo deportivo o artístico que se preocuparon por el desarrollo biológico, el disciplinamiento, el control, la estética o el movimiento. Así, se ha olvidado que el cuerpo también es un conjunto receptor de información, que puede transmitir mensajes, emociones, sensaciones y aprendizajes; también puede ser un dispositivo cargado de significación e interacción para la escuela.

Por otro lado, el cuerpo como construcción simbólica se ha relacionado directamente con las posturas teóricas de Le Breton (2002), quien realiza un estudio del mundo moderno desde una perspectiva antropológica y sociológica cuyo eje central es el cuerpo, las representaciones sociales y los saberes acerca del mismo definiéndolos como "tributarios de un estado social, una visión del mundo y una definición de la persona". El autor argumenta que el cuerpo es una construcción simbólica y no una realidad en sí misma, efecto de una construcción social y cultural. Considera que este funciona como un límite fronterizo que delimita la presencia del sujeto, factor de individuación, que en el plano social y el de 
las representaciones, está disociado del sujeto y es percibido como uno de sus atributos (p. 13).

En la modernidad el cuerpo se convirtió, además, en un objeto de negocio floreciente; la imagen del individuo se vinculó fuertemente al comercio y se desarrolló alrededor de la producción estética: el maquillaje, los gimnasios, los tratamientos para adelgazar, el mantenimiento de la forma y el desarrollo de terapias corporales. Sobre el cuerpo repercute fuertemente la imagen de la publicidad. Al respecto:

Hay un borramiento ritualizado del cuerpo, con el desarrollo de la ciencia y la tecnología hay un rechazo de la esfera corporal y una bienvenida a los arquetipos corporales insertados por la industria de la publicidad [...] los progresos técnicos y científicos con el vacío axiológico que significan, convirtieron el cuerpo humano en una mercancía. (Le Breton, 2002, pp. 9-23)

En la cultura del capitalismo se origina, en términos de Lipovetsky (1986), un cuerpo narcisista individualista. El autor habla de este individualismo como algo "desprovisto de valores sociales y morales del homo economicus, de la familia, la revolución y el arte" (p. 50). En la modernidad, el ser humano se caracteriza por ser mediático, por modificarse constantemente desde su pensamiento hasta su forma de verse frente al mundo; es momentáneo, disfruta los instantes presentes y se inscribe en el deseo de ser alguien y de ser diferente. En este sentido, el cuerpo es sometido a ritos de control y mantenimiento: la moda, el diseño, la publicidad y los mass media son los ingredientes que confluyen en la descorporeización denominada por Lipovetsky "desustanciación", que equivale a un desapego emocional, creándose así individuos aislados, vacíos y reciclables. Al respecto:

Los medios son como las extensiones del hombre; el ser humano, su cuerpo animal y sus funciones biológicas han pasado paulatinamente a las prótesis electromecánicas, "cuerpos simulacro" habitando un mundo imaginario y 
demiúrgico, "cuerpos virtuales", conectados a la gran red mass mediática por la que circula la cultura. (Lipovetsky, 1987, p. 107, citado en Domínguez, 2010, p. 63 )

Con la llegada de la tecnología y el acercamiento del otro mediante las redes sociales, los cuerpos mediáticos evocan la representación y la percepción de la propia imagen. Hay un interés en la representación individual y cómo el sujeto se ve para los demás. En este sentido, surge un afán desbordado de eternizar las acciones mediante fotos, videos, grabaciones y su respectiva reproducción para la viralización que, en últimas, es un afán descontrolado de ser reconocido y aceptado.

Al respecto, se considera que la vida humana transcurre en dos momentos: trabajo y ocio, pero los cuerpos buscan su aceptación tras la ceremonia del espectáculo y la exhibición. Estas condiciones, en las que cuerpo es signo de todo y válido para todo, lo llevan al vacío simbólico (Domínguez, 2010).

La sociedad contemporánea ha sido virtualizada, mediatizada y enajenada fuertemente por las nuevas tecnologías especialmente por la web. El ritual de la aceptación social de los jóvenes e incluso de los adultos por medio de likes se ha convertido en un fenómeno mediático arrollador, pues la web se ha vuelto la institución social por excelencia; se ha convertido en la materialización virtual-real de la iglesia, de la educación, de la política, de la familia. En otras palabras, se ha transformado en un organismo capaz de configurar los nuevos sentidos de las instituciones pilares por las que se rige la sociedad. Frente a esta perspectiva inquietante, la escuela proporciona espacios de aprendizaje a los sujetos que se encuentran desconectados del mundo real experimentando el fenómeno de la descorporeización vivida en cuerpos enajenados, y autómatas que reproducen en la realidad aquello que los identifica en la virtualidad.

Es una realidad social que hay padres que no tienen tiempo para sus hijos: largas jornadas de trabajo sumadas a los extenuantes y largos desplazamientos para cumplir jornadas laborales. Todo esto 
finalmente resulta en que las responsabilidades axiológicas son delegadas a un padre-educador virtual: "la Internet". Los jóvenes son entonces conducidos en su formación por sus nuevos maestros y padres inorgánicos, virtuales desconocidos, que no tienen censura frente a ningún tipo de información, edad, o acción moral. Pero, ¿por qué este fenómeno es desapercibido tanto para la escuela como para la estructura familiar?, ¿por qué padres y maestros no han reflexionado sobre las nuevas formas de abordar la información que en últimas terminan perfilando un nuevo ser social? y ¿qué hace que los jóvenes e incluso los adultos coexistan en un mundo cargado de violencia simbólica y esta pase desapercibida?

Este fenómeno se ha acrecentado y ha tomado fuerza en las últimas décadas. Le ha quitado potencia a la escuela como formadora integral y a la familia como pilar fundamental. Llama la atención especialmente la transformación que se ha dado sobre los discursos emergentes referentes al cuerpo que se han movilizado de manera mediática en la web. Tales discursos se han hecho virales y han sido apropiados y reproducidos por los jóvenes en las escuelas. En ellos, un nuevo concepto de cuerpo ha sido construido: un cuerpo denigrado y cosificado. Este se ha subvalorado como reflejo de una sociedad que juzga frecuentemente lo corpóreo.

Estos indicadores repercuten en gran medida en los procesos de aprendizaje de los estudiantes y en su relación con el entorno. En la escuela se evidencian situaciones que afectan el autoconcepto de los estudiantes y se reflejan en prácticas de diversos tipos que desembocan en experiencias juveniles mediadas por lo corpóreo: tatuajes, estilos de ropa o peinados, prácticas violentas sobre sí mismos como el cutting, las perforaciones, la cosificación corporal y el reconocimiento mediático del cuerpo; las enfermedades como la anorexia, la bulimia y en el peor de los casos el suicidio, entre otros fenómenos sociales, han emergido a partir de discursos mediatizados y movilizados desde la Internet que inciden en la descorporeización y repercuten en el aula tras la búsqueda de la identidad y el reconocimiento. 


\section{Metodología}

La propuesta investigativa es descriptiva, explicativa, de corte cualitativo enmarcado en el análisis lingüístico multimodal y el análisis hermenéutico y de contenido. El análisis del discurso multimodal es un paradigma emergente en los estudios del discurso que amplía el panorama en el estudio del lenguaje, incluyendo otras formas y recursos de comunicación. Mediante este proceso se analiza, se investiga y se recuperan patrones semánticos reconociendo a su vez que el contexto es esencial en todo análisis porque este determina patrones culturales y sociales (O'Halloran, 2012). Se pretende hacer una reflexión sobre los discursos juveniles culturales emergentes referidos al cuerpo que son apropiados y movilizados en la web. Con ello, se tiene el objeto de analizar las estrategias que instaura un discurso de lo corpóreo que ha sido desvirtuado y se traduce en un anclaje del espacio virtual al espacio real en donde intervienen elementos del yo social que son trasladados a la realidad educativa.

El estudio en el plano explicativo-cualitativo se interesa por develar el fenómeno de la descorporeización, movilizada y cristalizada en la web, como espejo de las representaciones sociales usadas por los jóvenes para inscribirse en el mundo anulando su propia identidad y materializando nuevas identidades y formas culturales que son naturalizadas en la interacción social. Posteriormente, tras el análisis de los discursos movilizados en la web sobre lo corpóreo, se identificaron los discursos apropiados y la relación del cuerpo en la escuela como lugar y mecanismo gestor de aprendizajes para finalmente proponer una estrategia pedagógica que recupere el cuerpo en el proceso de enseñanza-aprendizaje.

Para completar el proceso de investigación, se aplicaron cuestionarios y encuestas a un grupo de jóvenes. Estas indagaron sobre el uso, movilización y apropiación de contenidos de las nuevas tecnologías en relación con las representaciones sociales creadas del cuerpo, y, por otro lado, sobre la percepción del cuerpo en la escuela desde la perspectiva de los adolescentes y la perspectiva de 
los maestros. Dichos instrumentos determinaron elementos claves de revisión para la identificación del fenómeno de la descorporeización en la escuela.

La población de análisis se centró en un grupo de jóvenes entre 16 y 20 años del colegio José María Vargas Vila y egresados de esta institución, ubicada en la periferia de la ciudad de Bogotá, quienes evidencian intereses particulares a elementos referidos a los contenidos de las redes sociales. Las muestras de análisis fueron las expresiones monomodales y multimodales referidas al cuerpo evidenciadas en las redes sociales y el portal YouTube que han sido apropiadas, movilizadas e interiorizadas interviniendo en la construcción de un nuevo yo y un nuevo autoconcepto corporal desde la mediatización. Se elige esta población pues llama la atención su autorreconocimiento de cuerpo (atravesado por patrones massmediáticos) y los tratamientos que le dan a este desde lo discursivo o desde lo físico-corpóreo para ser aceptado socialmente por su contexto inmediato (llámese escuela, barrio o universidad).

Esta población escogida conforma los usuarios de Internet que según los datos arrojados por el Estudio del Centro Nacional de Consultoría (CNC) revelan el nivel de apropiación digital en Colombia. De acuerdo con la información aportada, quien más uso hace de Internet y quien más horas permanece conectado se encuentra en el rango de edad de entre los 18 y 24 años. Los criterios de control para la muestra fueron el nivel educativo, la edad y el sexo.

El estudio elaborado por la universidad Eafit y Tigo titulado ¿Cómo usan los niños y adolescentes colombianos las herramientas de Internet?, revela cómo los jóvenes de 9 a 16 años interactuan en la red; el estudio arroja que entre mayor edad más conexión. La población escogida para la investigación, conforma los usuarios de Internet que en este rango de edad permanecen más tiempo conectados.

El nivel educativo interesó por la necesidad de conocer si el nivel de estudios en el que se encuentran los jóvenes es determinante para la apropiación del material circundante en la web. El 
segundo criterio para seleccionar la muestra fue el sexo ya que, en el estudio mencionado anteriormente, se demuestra que hay una pequeña diferencia en el uso que hacen hombres y mujeres, donde los hombres en Colombia son más digitales que las mujeres y pasan más tiempo conectados. El interés en este criterio está en determinar cuáles son los contenidos movilizados en el espacio virtual tanto por hombres como por mujeres y en qué medida estos contenidos son apropiados e interiorizados por los cibernautas.

De esta manera se emplearon instrumentos de análisis referidos a cuestionarios y encuestas aplicadas en un pilotaje a 20 jóvenes (10 hombres y 10 mujeres) que se encuentran cursando los últimos grados escolares.

El acercamiento al material de reflexión apunta, por encima de la descripción y cuantificación de los datos, a una reflexión de corte epistémico de las acciones y mecanismos infundados en la web para la construcción de un nuevo concepto de cuerpo traducido en un discurso mediático-social.

La investigación en curso ha avanzado hasta la caracterización del fenómeno y el análisis lingüístico multimodal que evidencia el concepto de cuerpo movilizado en Internet y apropiado por los jóvenes.

Para el análisis cualitativo de las prácticas que llevan a cabo los jóvenes a través de las redes sociales se hizo una revisión de sus rutinas digitales y los significados que le dan a la relación de estos medios que permiten la comunicación y apropiación cultural. Además, se indagó por el sentido referido al reconocimiento histórico, sociocultural y apropiación del corpus. Esto y un rastreo de lo corporal en la virtualidad y sus manifestaciones discursivas, permitieron, en un segundo momento, identificar el significado otorgado por los jóvenes al uso de las redes sociales y a los discursos corporales movilizados.

Posteriormente, se desarrolló un análisis descriptivo y caracterización del corpus a partir de los resultados arrojados por los ins- 
trumentos aplicados. De esta manera, se caracterizó el fenómeno de lo corpóreo en la web, sus rasgos y propiedades discursivas y las condiciones que exige el medio que lo difunde.

Finalmente, se hizo un análisis en perspectiva cualitativa del corpus, centrado en un análisis de los rasgos y recursos discursivos y semióticos que caracterizan la muestra seleccionada, la cual se destaca por su relevancia mediática y su carácter viral.

\section{Resultados y discusión}

A partir de las encuestas desarrolladas se identificó que la dinámica que se genera en torno a la Internet toma mayor relevancia con el uso de las redes sociales a las que acceden y a las cuales pertenecen los jóvenes. Estas cumplen el papel de factor generador de gustos y preferencias relacionadas con la moda, los grupos de interacción y temas específicos. Facebook es la red social más usada y es la que les permite sentirse en conexión con el mundo; seguidamente, el uso del portal YouTube en el que ven videos que les llaman la atención y que están relacionados con temas musicales, o de su preferencia.

En este apartado, cobra especial interés la importancia brindada a los fenómenos de Youtubers, pues las encuestas arrojaron que se sienten identificados con lo que dicen estos personajes en sus canales, su forma de expresarse, vestirse y los chistes que hacen en la presentación de sus programas. Entre los canales de Youtubers más visitados por este grupo de estudiantes y que coinciden con ser los más populares de la red, se encuentran: Sebastián Villalobos, DrebRyanShow, Jonathan Clay, Matu Garcés, Juan de Dios, Kimberly Loaiza y otros de menor relevancia para el grupo de jóvenes encuestados.

Los modos discursivos, la percepción y formas de trato entre sí que han sido adoptados por los jóvenes, y que se ha evidenciado en este estudio, tiene mucha influencia del fenómeno virtual. Si 
bien, los medios masivos de comunicación son instituciones modernas de producción discursiva, estas están insertas en otras instituciones, ya sea de carácter político, económico, cultural, religioso o educativo. Tienen como función más que difundir, relacionar formas de interpretar y representar la realidad (Pardo, 2008a). Se entienden como medios no neutrales, que controlan el contenido de los discursos, privilegiando ciertas visiones del mundo de otras que anulan, lo que los hace, en algunos casos, más cercanos o distantes de lo oficial. Internet es un medio que integra una infinidad de discursos, a los que se accede por medio de un proceso interactivo, caracterizado por su inmediatez y su carácter global, en el que la comunicación es multimodal. Los jóvenes acceden a múltiples ventanas en su computadora para interactuar con el mundo virtual que se convierte en el mundo paralelo al mundo real.

Por su parte, el portal YouTube, tiene como objetivo divulgar, publicar y compartir videos de forma gratuita, con una recepción masiva, que hace de sus productos (videos y presentaciones Power Point), discursos públicos. Tal situación es posible por su facilidad para usar formatos de video comunes, como: WMV, AVI, MOV, EG o MP4, y de audio, como el formato MP3; en él, cualquiera puede transferir un contenido a formatos digitales en tamaños que oscilan entre $100 \mathrm{MB}$ a $1 \mathrm{~GB}$ sin la necesidad de programas complementarios o registros previos, opción voluntaria del portal. Hay una circulación libre de contenidos y una producción simbólica,en la que los usuarios legitiman o deslegitiman determinados discursos.

La relación temática del portal YouTube radica, según Pardo (2008b), en "develar macrotemas expresados en videos". Es decir, tiene la capacidad de vincular otros videos relacionados con el tema registrado en el buscador. Lo anterior apunta a la jerarquización de la información, atendiendo a lo más popular y a lo más buscado y disponiendo la información que le interesa al usuario mediante Tag Clouds que mezclan o definen el peso de cada tag. Estas últimas son etiquetas que conforman el lenguaje HTML (lenguaje utilizado para escribir páginas de hipertexto). Los tags son comandos que los programas navegadores leen e interpretan para 
armar las páginas de Internet. Esta jerarquización temática, además de ser interactiva, cumple con una función cognitiva, al activar un conjunto de conocimientos que, en la praxis, llevan a los usuarios a identificar fuentes más viables y pertinentes a sus necesidades de búsqueda.

YouTube es un sitio que permite relaciones intertextuales e hipervínculos mediante tags. Además, es uno de los portales más visitados en el mundo, en el que se concentran significados construidos que se relacionan con el usuario, lo que permite un significado social movido desde la mediatización. Este es el lugar predilecto para analizar las representaciones sociales circundantes, con aparente libertad, en tejidos de hipervínculos y que inciden en amplios sectores de la sociedad.

El fenómeno de los Youtubers y su relación con los jóvenes, como todas las modas, incide en la transformación cultural y tiene injerencia en la construcción social. Este fenómeno determina en los jóvenes formas de actuar, pensar, vestir, hablar y comportarse. Su creciente popularidad se da a partir de la autonomía que tienen los mismos jóvenes de descubrir y determinar quiénes son sus ídolos, permitiendo una "democratización" en la cultura juvenil, convirtiéndose en nuevos hábitos de consumo.

Un adolescente YouTuber puede llegar a tener millones de seguidores sin necesidad de ayudas, contratos, o inversiones millonarias y puede lograr más popularidad que un artista de carrera, llámese, músico, escritor o actor. Por ejemplo, en nuestro caso: Sebastián Villalobos cuenta con 6692872 suscriptores; DebryAnshow, con 9 263 784; Matu Garcés, con 2543 063; Jonathan Clay, con 2344 621; Kimberly Loaiza, con 17122 610; Juan de Dios Pantoja, con 15320 210 seguidores. Cabe mencionar que el número de suscriptores y reproducción de sus videos se traduce en cifras multimillonarias. Pero, ¿cuál es el contenido que los conecta con los otros jóvenes y enriquece sus bolsillos?

Los resultados arrojados en las encuestas demuestran que los Youtubers más populares utilizan el humor y refieren a temas ba- 
nales y actividades cotidianas. Pero también es interesante ver que tienen un contacto virtual con sus seguidores quienes proponen temas para sus videos; a partir de allí, abordan diversos contenidos como los videojuegos, las críticas referidas a cualquier tema o persona, los videoblogs, la belleza, bromas desde las más inocentes a hasta las más peligrosas, tutoriales, entre otros. Los Youtubers más vistos por la población entrevistada, y que son de hecho los más populares y virales en Colombia y en Latinoamérica, practican el fenómeno de los retos que se han vuelto virales, muchos de ellos de carácter corporal; sencillos o peligrosos, algunos son de un carácter sexual marcado y quien los ejecuta es aceptado en un grupo determinado. En otras palabras, estos retos pueden leerse como la actividad estipulada que permite otorgarle a quien la practica un carácter de poder y aceptación.

En los resultados se identificó que los estudiantes de sexo masculino se identificaban con Youtubers masculinos. Estos últimos producen videos de todo tipo, pero los más virales eran referidos a los retos, sencillos, peligrosos y otros de carácter sexual; por su parte, las mujeres se identificaban con Youtubers femeninas, cuyos contenidos de sus videos referían a temas de la cotidianidad, moda y belleza, ratificando un estereotipo de mujer. Aunque el espacio es virtual, el tema corporal es muy importante porque está mediado por cómo se ven los jóvenes y cuál es su prototipo para reproducir socialmente en la escuela. Los jóvenes reproducen formas de sus ídolos expresiones lingüísticas, peinados, e incluso imitan posturas corporales de sus Youtubers favoritos para ser reproducidos en el espacio real de la escuela. La atracción por lo banal es algo nuevo en esta época; la web 2.0 lo ha permitido. Los Youtubers son idolatrados por jóvenes que buscan autoafirmarse y construir su identidad.

A continuación, en las tablas 1,2 y 3 se presentará una rejilla que resume a grandes rasgos, los aspectos más importantes de los videos más virales y con mayores seguidores de los Youtubers más seguidos. 
Tabla 1. Video de DebRyanShow.

\begin{tabular}{|c|c|c|}
\hline $\begin{array}{l}\text { Elemento de } \\
\text { análisis }\end{array}$ & Observaciones & Otras anotaciones \\
\hline Autor & DebRyanShow & \\
\hline Título & Tag del supermercado & \\
\hline $\begin{array}{l}\text { Resumen del } \\
\text { contenido }\end{array}$ & $\begin{array}{l}\text { Deby y su novia visitan el supermercado } \\
\text { vestidos de pijama. Él lleva una lista } \\
\text { que le envía su mamá para hacer } \\
\text { el mercado. Hacen comentarios y } \\
\text { recomendaciones para las compras. }\end{array}$ & $\begin{array}{l}\text { Los personajes visitan el } \\
\text { supermercado disfrazados de } \\
\text { animales, elemento que los muestra } \\
\text { como personajes irreverentes. Durante } \\
\text { el video se utilizan textos para aclarar } \\
\text { algunos significados y sonidos } \\
\text { extradiegéticos. }\end{array}$ \\
\hline Personajes & Deby y su novia & $\begin{array}{l}\text { Se refiere a su novia como la esclava, } \\
\text { lo hace llevarlo en el carrito del } \\
\text { mercado como si fuera su chofer, le } \\
\text { lanza un rollo de papel higiénico y la } \\
\text { golpea en la cara burlándose de ella. }\end{array}$ \\
\hline Temática & Vida cotidiana, humor & $\begin{array}{l}\text { Hablan con personas del } \\
\text { supermercado, acción que los acerca } \\
\text { más hacia el público. El Youtuber es } \\
\text { reconocido allí. }\end{array}$ \\
\hline Duración & $14: 31$ & \\
\hline $\begin{array}{l}\text { Fecha de } \\
\text { publicación }\end{array}$ & 11 de abril del 2017 & \\
\hline Respuestas & 39000 & $\begin{array}{l}\text { Uno de los videos más vistos del } \\
\text { canal. }\end{array}$ \\
\hline $\begin{array}{l}\text { Número de } \\
\text { visitas }\end{array}$ & 8130213 & \\
\hline
\end{tabular}

Fuente: elaboración propia.

Tabla 2. Video de Sebastián Villalobos.

\begin{tabular}{|c|c|c|}
\hline $\begin{array}{l}\text { Elemento de } \\
\text { análisis }\end{array}$ & Observaciones & Otras anotaciones \\
\hline Autor & $\begin{array}{l}\text { Sebastián Villalobos y Mario Ruiz (FT. } \\
\text { Juapa Zurita) Sebastián Villalobos. }\end{array}$ & \\
\hline Título & Reto de retos & \\
\hline $\begin{array}{l}\text { Resumen del } \\
\text { contenido }\end{array}$ & $\begin{array}{l}\text { El video es una compilación de retos } \\
\text { que cumplen los dos Youtubers, retos } \\
\text { como golpearse la cabeza con una } \\
\text { manzana hasta romperla, la mayor } \\
\text { cantidad de medias que puedan } \\
\text { ponerse, inflar un condón hasta que } \\
\text { explote, ponerse limón en los ojos, } \\
\text { comer canela en polvo, comer aguacate } \\
\text { y sandía en el menor tiempo posible, } \\
\text { golpearse con pescado podrido. }\end{array}$ & $\begin{array}{l}\text { Durante el video se utilizan textos para } \\
\text { enfatizar algo y música extradiegética } \\
\text { y en algún punto se vuelven sonidos } \\
\text { relacionados con una canción de } \\
\text { Bruno Mars. }\end{array}$ \\
\hline Personajes & Sebastián Villalobos y Mario Ruiz & $\begin{array}{l}\text { La mayoría de los retos propuestos } \\
\text { violentan su propia corporalidad y } \\
\text { algunos son peligrosos, se golpean, a } \\
\text { sí mismos, golpean al otro, y ponen en } \\
\text { riesgo su vida. }\end{array}$ \\
\hline
\end{tabular}




\begin{tabular}{|c|c|c|}
\hline $\begin{array}{c}\text { Elemento de } \\
\text { análisis }\end{array}$ & Observaciones & Otras anotaciones \\
\hline Temática & Retos, humor & \\
\hline Duración & $13: 58$ & Uno de los videos más vistos del \\
\hline $\begin{array}{c}\text { Fecha de } \\
\text { publicación }\end{array}$ & 15 de marzo del 2016 & \\
\hline $\begin{array}{c}\text { Respuestas } \\
\text { Número de } \\
\text { visitas }\end{array}$ & 15000 & \\
\hline
\end{tabular}

Fuente: elaboración propia.

Tabla 3. Video de Kimberly Loaiza.

\begin{tabular}{|c|c|c|}
\hline $\begin{array}{l}\text { Elemento de } \\
\text { análisis }\end{array}$ & Observaciones & Otras anotaciones \\
\hline Autor & Kimberly Loaiza & \\
\hline Título & Le digo a Juan que me vuelva a besar & \\
\hline $\begin{array}{l}\text { Resumen del } \\
\text { contenido }\end{array}$ & $\begin{array}{l}\text { El video es una compilación de retos } \\
\text { propuestos por los seguidores de la } \\
\text { Youtuber, estos retos debe cumplirlos } \\
\text { en tiempo real. Los retos incluyen } \\
\text { gritar cosas por la ventana, bailar } \\
\text { en semáforos, tomarse fotos con } \\
\text { desconocidos, darle comida y dinero } \\
\text { a personas pobres, hacer llamadas } \\
\text { y hacer bromas, golpearse con una } \\
\text { manzana, quemarse la piel con sal y } \\
\text { hielo, entre otros. }\end{array}$ & $\begin{array}{l}\text { Durante el video se utilizan textos y } \\
\text { sonidos extradiegéticos para enfatizar. } \\
\text { Uso de música electrónica para el } \\
\text { cabezote de los videos. } \\
\text { Utiliza textos que refuerzan lo que se } \\
\text { dice o se piensa como si fuese una } \\
\text { caricatura. Se distorsiona la voz de } \\
\text { la Youtuber para darle un carácter de } \\
\text { humor. } \\
\text { Se refiere a sus seguidores } \\
\text { constantemente con el apelativo de } \\
\text { "linduras". } \\
\text { El video se realiza en un lugar muy } \\
\text { común: una habitación, que denota un } \\
\text { contenido fresco para los adolescentes } \\
\text { y de poca producción. }\end{array}$ \\
\hline Personajes & Kimberly Loaiza & $\begin{array}{l}\text { La mayoría de los retos propuestos } \\
\text { están relacionados con el pudor y } \\
\text { la ética, hacer pasar vergüenzas } \\
\text { a la Youtuber es el objetivo de los } \\
\text { seguidores y cumplir estos retos es } \\
\text { sinónimo de acercamiento a ellos. } \\
\text { Algunos retos están relacionados con } \\
\text { experiencias físicas, como violentar } \\
\text { su cuerpo. } \\
\text { El desarrollo de estos retos y la } \\
\text { integración de personas del común } \\
\text { también acerca más al público, } \\
\text { estrechando el vínculo entre Youtuber } \\
\text { y seguidores. }\end{array}$ \\
\hline
\end{tabular}




\begin{tabular}{|c|c|c|}
\hline $\begin{array}{c}\text { Elemento de } \\
\text { análisis }\end{array}$ & Observaciones & Otras anotaciones \\
\hline Temática & Retos, humor & \\
\hline Duración & $11: 18$ & Uno de los videos más vistos del \\
canal. \\
\hline $\begin{array}{c}\text { Fecha de } \\
\text { publicación }\end{array}$ & 23 de noviembre 2017 \\
\hline $\begin{array}{c}\text { Respuestas } \\
\text { vúmero de } \\
\text { visitas }\end{array}$ & 821000 & \\
\hline
\end{tabular}

Fuente: elaboración propia.

Como puede observarse, los Youtubers que más ven los adolescentes colombianos, movilizan diferentes discursos y actitudes que influyen en la construcción de la identidad adolescente, pues ellos se convierten en los modelos de conducta y pensamiento. Estos personajes basan sus videos en productos de poca producción técnica, y de contenido, de esta manera pueden grabar desde su celular en cualquier parte de su casa cualquier contenido vacío que será reproducido millones de veces por los adolescentes. Asimismo, es interesante ver cómo los jóvenes han adoptado los discursos movilizados por estos personajes (vestido, expresiones lingüísticas y corporales) para identificarse y ser reconocidos y aceptados en su círculo social.

\section{Los memes y la cosificación corporal}

¿Qué comparten los jóvenes en sus redes sociales? La totalidad de los jóvenes encuestados, afirmó que la mayoría de sus publicaciones compartidas eran memes, que referían a hechos cotidianos, aspectos faranduleros o burlas de personas. A partir de esta respuesta, se indagó por los memes más virales y reproducidos en la red. Y se encontraron memes con alta carga significativa detrás de la dosis de humor.

Un meme es una idea, un comportamiento, un estilo o una manera de ser que se propaga de un individuo a otro en el seno de 
una cultura (Dawkins, 1993). Un meme es el retrato de emociones y experiencias de manera sarcástica, fragmentos de la realidad que otorgan nuevos significados; es considerado por algunos como un arte vulgar. Los memes pertenecen a todos, quien los crea, los consume, los comparte, con quien se identifica, es un nuevo lenguaje que denota la existencia y burla de la humanidad.

El poder de los memes ha sido predominante en el desarrollo cultural y económico de los países que tienen un alto acceso a Internet. Al respecto, McLuhan y Powers (1990) consideran que:

La tecnología computacional cambiará el mundo convirtiéndolo en la "aldea global". [...] los medios al modificar el ambiente, suscitan en nosotros percepciones sensoriales de proporciones únicas. La prolongación de cualquier sentido modifica nuestra manera de pensar y de actuar - nuestra manera de percibir el mundo-. Cuando esas proporciones cambian los hombres cambian. (p. 41)

Los memes impactan porque reúnen las vivencias y motivaciones de las personas, crean mensajes sencillos que calan en la memoria cuya función es conmover, gustar, violentar, hacer reír, incitar al consumo o la adopción de ideas; estos evidencian la simplicidad de una situación, versus la realidad que se presenta. De esta manera, se puede encontrar memes con alta carga significativa; por un lado están aquellos que critican la realidad social y política, por otro lado aquellos que se burlan de la cotidianidad y por último aquellos que tienen alto contenido de violencia simbólica.

Los memes describen quiénes somos y lo que pensamos, produciendo una sensación de comprensión y pertenencia. Su poder está en la brevedad y la simplicidad que es el reflejo de la sociedad, básica, vacía, poco crítica y moldeable, a modo de ejemplo figura 1. 


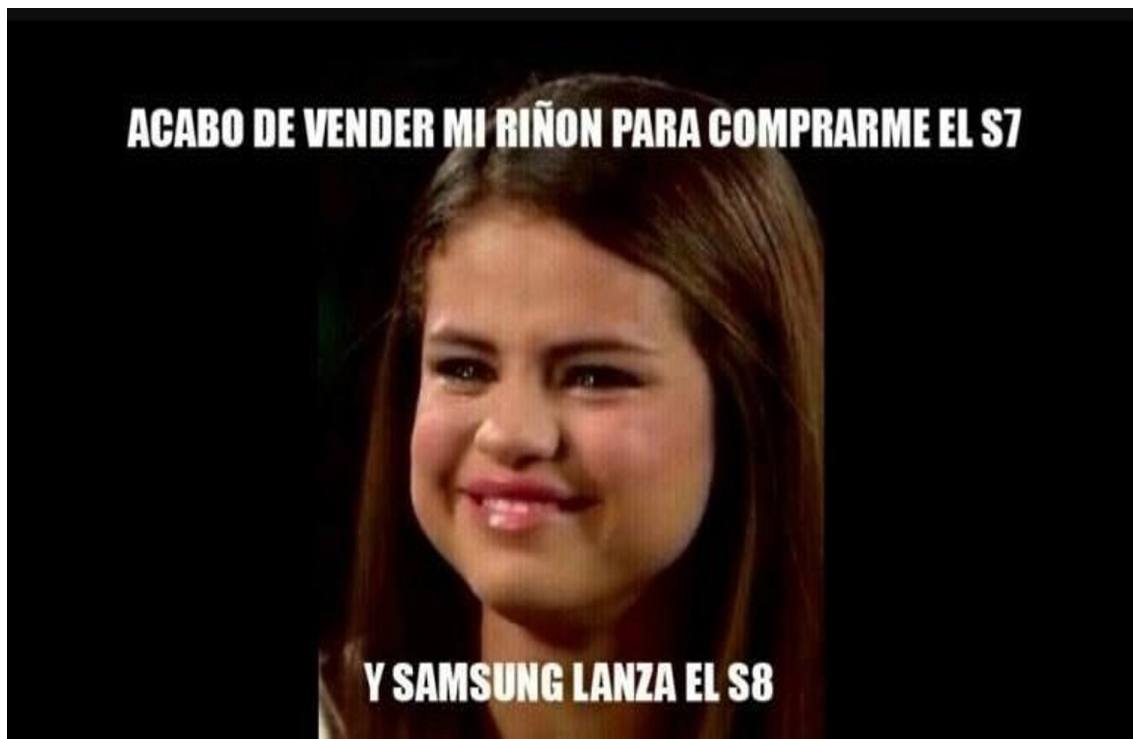

Fuente: https://larepublica.pe/tecnologia/1202857-samsung-galax9-s9-crueles-memes-se-burlan-delnuevo-smartphone-fotos

Con la viralización en Internet se puede advertir que en diferentes grupos geográficos existe un lazo de comunicación que los une. Así, el contenido reproducido en un país es fácilmente movilizado en otro $y$, en últimas, la replicación no es solo del meme sino de la unidad de sentido que esta transporta. El meme presenta, bajo esta teoría, un potencial de replicación transversal o longitudinal, ya que es empleado por muchas personas de manera reiterada y puede mantenerse a lo largo del tiempo y del espacio, formando parte de una cultura. Indudablemente, posee un potencial comunicativo con un sentido compartido. Un "nodo de memoria semántica" o un conjunto de signos en pleno sentido.

Los memes se han convertido en unidades semánticas capaces de evocar los significados a los que están asociados y el proceso de evocación y la eficacia del meme es disparador de atención, recuerdo y repetición del significado adscrito, esto es lo que los vuelve relevantes (Lissack, 2004, citado por Pérez, Aguilar y Guillermo, 2004, p. 81). 
¿Qué muestran los memes de nuestra sociedad? Al revisar su viralidad, se puede identificar que hay memes que prestan especial interés a la mujer desde una nueva significación. La personificación, cosificación y burla presentes en el sentido original de los memes referidos a lo femenino causan gran interés, pues es la idea de mujer que se moviliza en la virtualidad y que despliega una nueva simbolización del papel de esta en la sociedad; este nuevo concepto se ha naturalizado y camuflado en el humor. Al respecto, se pueden encontrar memes que le dan atributos a la mujer desde la personificación animal, por ejemplo las descripciones resentadas en las figuras 2 al 4.

Figura 2. Meme animalizando a la mujer $n .^{\circ} 1$.

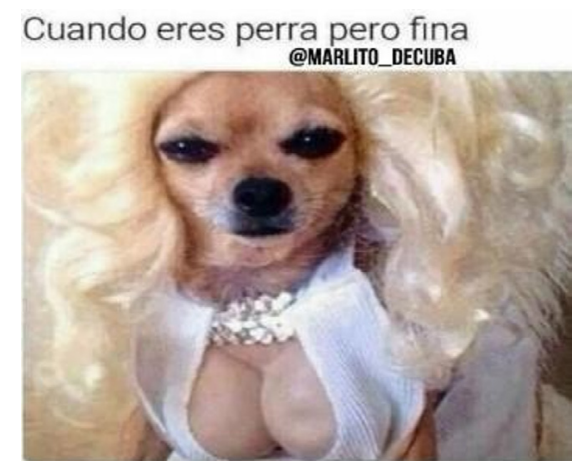

Fuente: Me.me (21 de junio de 2017). Cuando eres perra pero fina otcame no meme. Recuperado de https://me.me/i/cuando-eres-perra-pero-fina-otcame-no-15668939

Figura 3. Meme animalizando a la mujer $n .^{\circ} 2$.
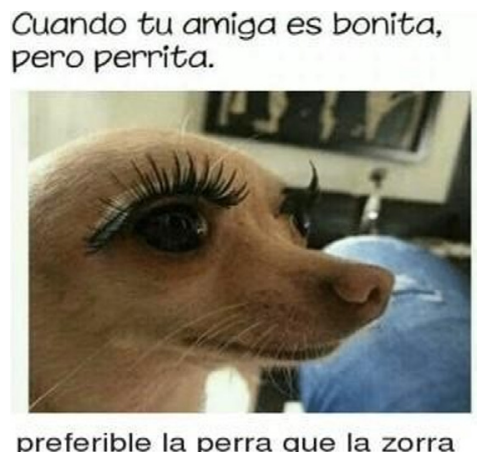

Fuente: Dopl3r. (s. f.). Memes y gifs de animales. Recuperado de https://www.dopl3r.com/memes/ animales/cuando-tu-amiga-es-bonita-pero-perrita/196378 
Figura 4. Meme animalizando a la mujer $n .^{\circ} 3$.

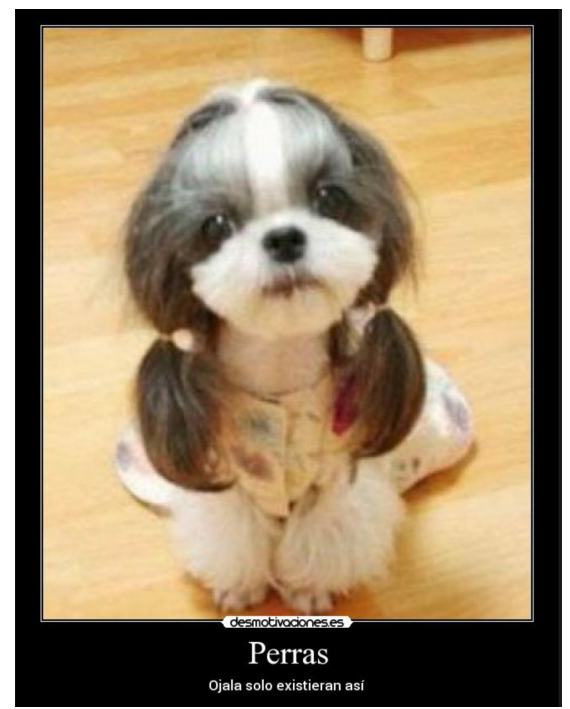

Fuente: Jorgeribero10. (19 de mayo de 2011). Perras. Desmotivaciones.es. Recuperado de https:// desmotivaciones.es/1518180/Perras

La caracterización de la mujer en memes desde la personificación animal (especialmente una perra) es un hecho que se ha naturalizado en las redes y su significado connotado alude a una agresión ética social y una crítica al comportamiento femenino. Rasgos como la peluca, el color de la peluca, los senos, el cabeIlo, las pestañas postizas son elementos visuales que ridiculizan y agreden el rol femenino. Los textos que acompañan la imagen: "cuando eres perra pero fina"; "perras, ojalá solo existieran así"; "cuando tu amiga es bonita, pero perrita"; "preferible la perra que la zorra", hacen un uso metafórico y de recursos estilísticos para fijar más su significado en el espectador y crea un nuevo concepto de mujer; el sentido humorístico le da el toque impersonal. Se puede agredir mediante la risa y esto es socialmente aceptado y naturalizado. figura 5 y 6 . 
Figura 5. Meme de burla a la mujer $n .^{\circ} 1$.

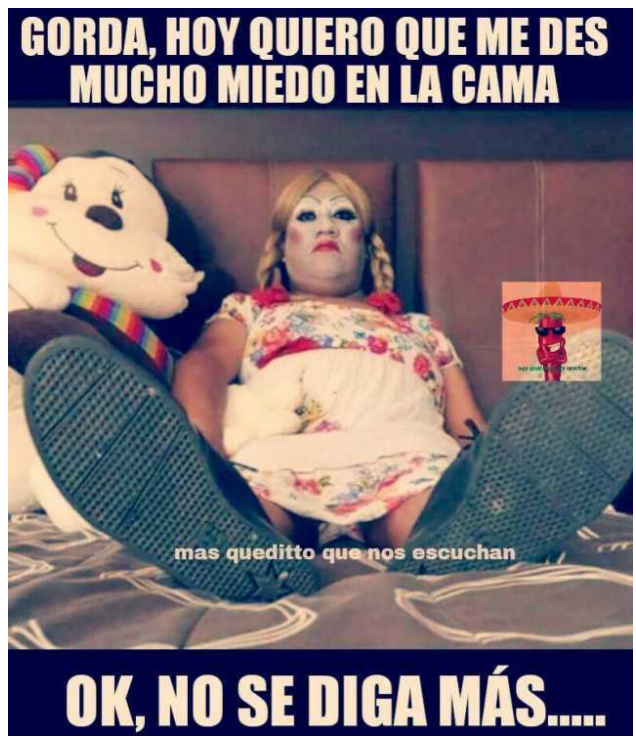

Fuente: Dopl3r. (s. f.). Memes y gifs graciosos. Recuperado de https://www.dopl3r.com/memes/ graciosos/gorda-hoy-quiero-que-me-des-mucho-miedo-en-la-cama-mas-queditto-que-nos-escuchan-okno-se-diga-mas/117915

Figura 6. Meme de burla a la mujer $n .^{\circ} 2$

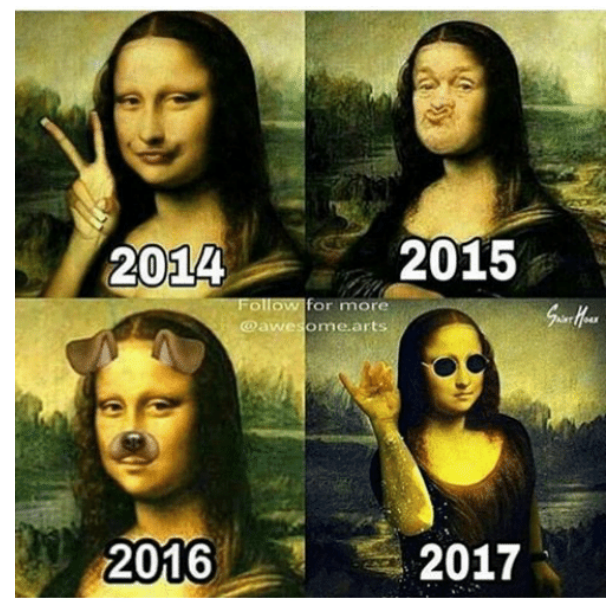

the saltbae meme is so good.

Fuente: BxtchltzPeyton. (30 de abril de 2017). The Mona-Lisa Memes. Recuperado de https://imgur. com/gallery/bdy0Q 
La caricaturización de la mujer en la web es otro elemento latente que cobra fuerza no solo desde la viralización de los memes sino también desde los videos presentados por Youtubers populares que se encargan de ridiculizar el rol femenino desde varios aspectos (figuras 7 y 8 ).

Figuras 7 y 8 . Fragmentos de videos de Jonathan Clay.

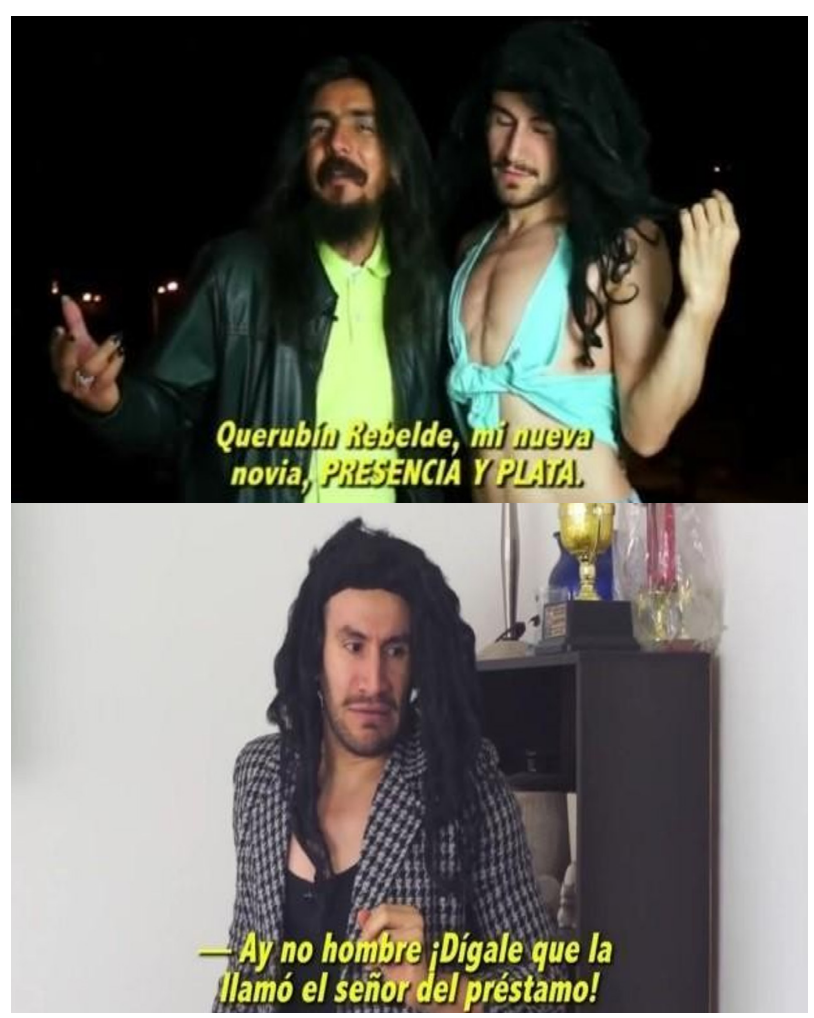

Fuente: videosdetodo (18 de marzo de 2017). Lo que callamos los hijos de Jonathan Clay/Videos de Todo. Recuperado de https://www.youtube.com/watch?v=gCdwcDehK5Q

La sexualización y cosificación de la mujer es un aspecto interesante de revisar pues se ha naturalizado y banalizado el aspecto sexual (figuras 9 y 10). En el instrumento aplicado a los estudiantes se indagó por cómo veían ellos prácticas como el sexting. En su mayoría refirieron que no lo practican, pero un gran porcentaje conoce a alguien que sí lo hace, considerándose una práctica normal entre los adolescentes, en la que cada quien es libre de hacer 
con su cuerpo lo que quiera. Sin embargo, cuando se les preguntó cómo leían ellos el manejo que se daba de la corporalidad en la web, sus respuestas se centraron en que la Internet incita a la sexualidad, la promiscuidad, y el desapego del cuerpo en un escenario en el que se es agredido, y violentado. Tales acciones se han naturalizado en un mundo virtual y trastocan el mundo real; en él ya no hay espacio para la intimidad y es necesario informar constantemente lo que se hace o se deja de hacer como forma de interactuar con el mundo y pertenecer a la sociedad.

Figura 9. Meme de burla a la mujer $n .^{\circ} 3$

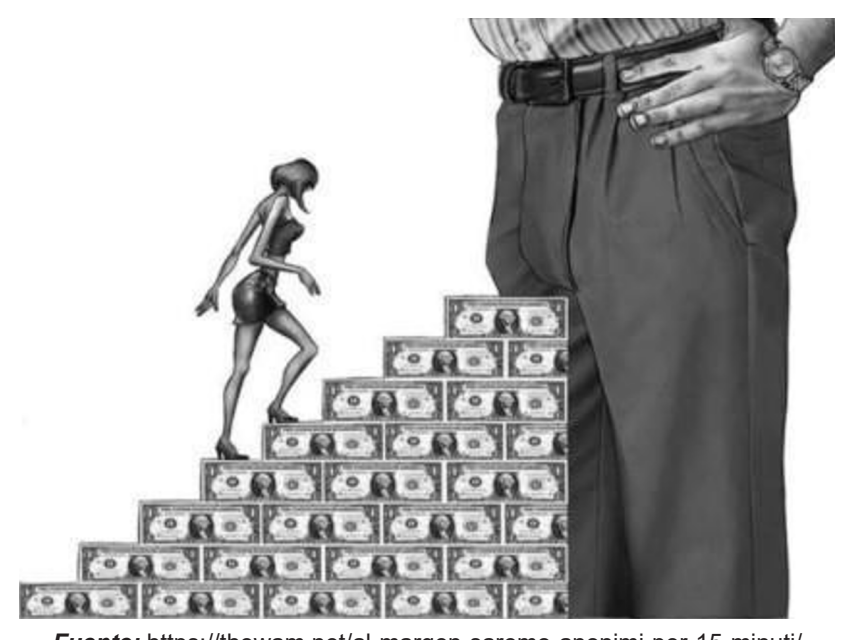

Fuente: https://thewam.net/al-margen-saremo-anonimi-per-15-minuti/

Figura 10. Memes de burla a la mujer $n .^{\circ} 4$

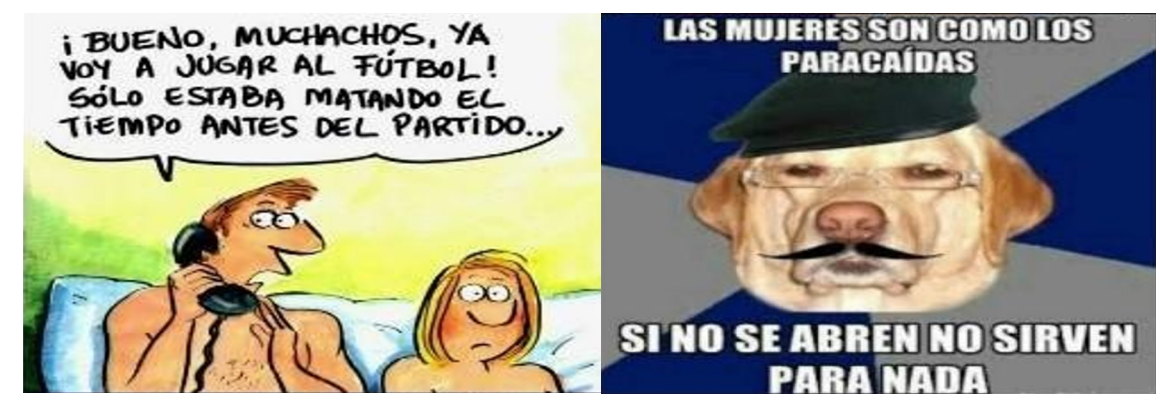

Fuente: MemeGenerator. (s. f.). Perro machista. Recuperado de https://memegenerator.net/ instance/14702011/perro-machista-las-mujeres-son-como-los-paracadas-si-no-se-abren-no-sirven-paranada 
El cuerpo ha sido entonces descorporeizado en la web, la línea fronteriza entre la lo real virtual y lo real social se ha desdibujado. Encontramos chicos que no tienen identidad propia, han adoptado posturas corporales, léxico, ideas, formas de referirse al mundo de sus ídolos virtuales. El cuerpo real es reflejo de los cuerpos virtuales, cuerpos que se venden, se exhiben son sexualizados y materializados desde la banalidad internáutica; como se expresa en la figura 11. El cuerpo ya no vale, no siente, no hay que cuidarlo; el fenómeno de los retos es un ejemplo de cuánto puede costar la vida; cuerpos agredidos, caricaturizados, desvirtuados, en el afán mediático de ser aceptado.

Figura 11. Tristes realidades de nuestra sociedad.

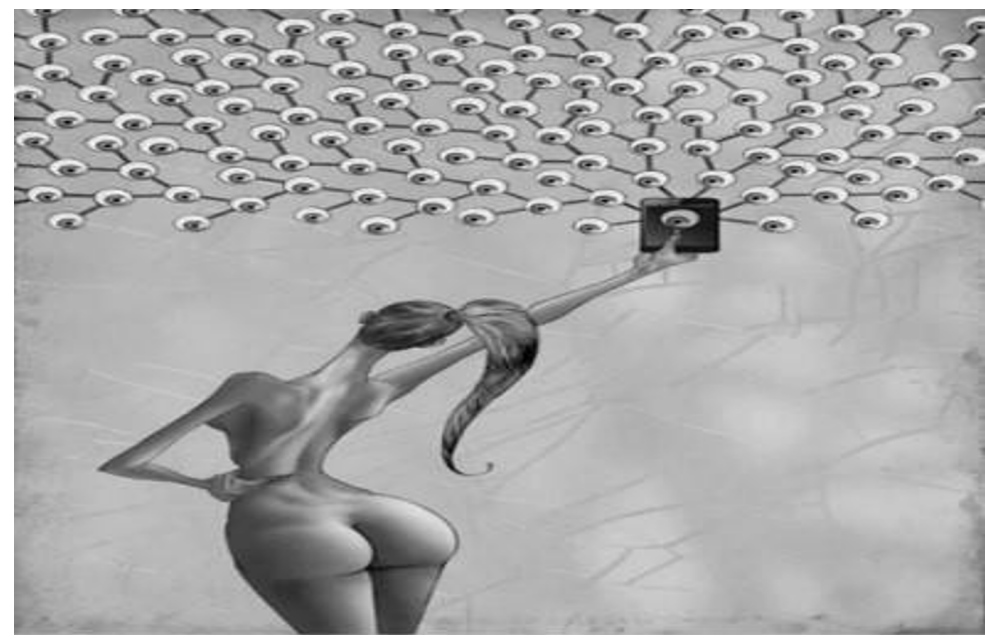

Fuente: https://www.pinterest.es/pin/123708320997505152/

Por otro lado, se evidencia el fenómeno relacionado con la dismorfia corporal. Tal fenómeno toma fuerza en la adolescencia, en la que el individuo está más preocupado de su autoimagen y la vida social. Internet influye drásticamente en el prototipo social "aceptado" pues es un refuerzo del ideal de belleza, su importancia y cómo alcanzarlo, proporcionando un referente para comparar. La preocupación por el aspecto físico, la autoimagen y la sobrevaloración del cuerpo afecta a hombres y mujeres por igual. La idea de la felicidad y del éxito, se canaliza a través de lo estético; dis- 
tintos mecanismos para alcanzarlo (dietas, trucos para verse más delgados o más fitness, tutoriales de maquillaje, etc.) abundan en las redes sociales, creando una insatisfacción o alteración de la imagen corporal. En algunos casos se evidencian comportamientos autodestructivos que pueden significar la muerte.

Figura 12. Barbie humana, Valeria Lukyanova.

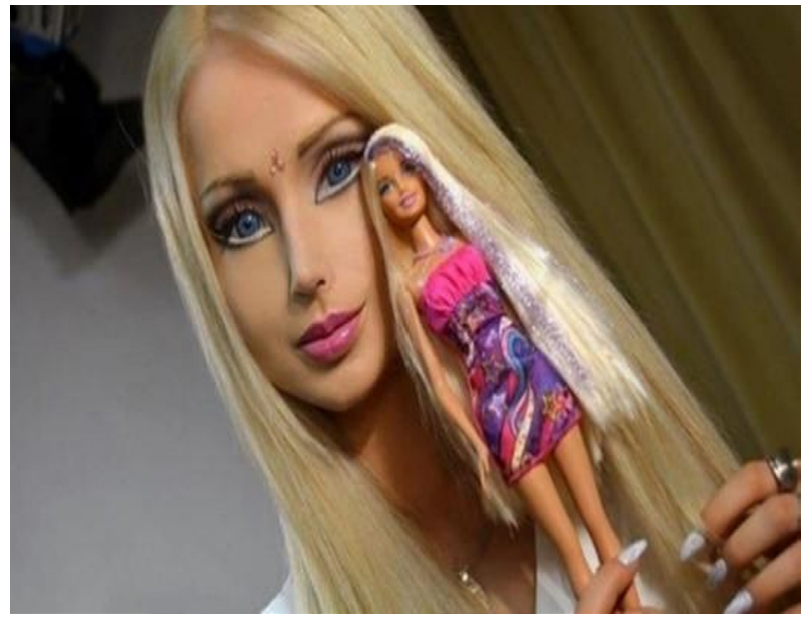

Fuente: Raya, S. (2 de diciembre de 2016). La Barbie humana muestra su verdadera cara. Curiosidades y cosas insólitas. ABC Blogs. Recuperado de http://abcblogs.abc.es/curiosidades-cosasinsolitas/2016/12/02/valeria-lukyanova-barbie-humana-cara- verdadero-rostro-real/

Figura 13. La transformación humana.

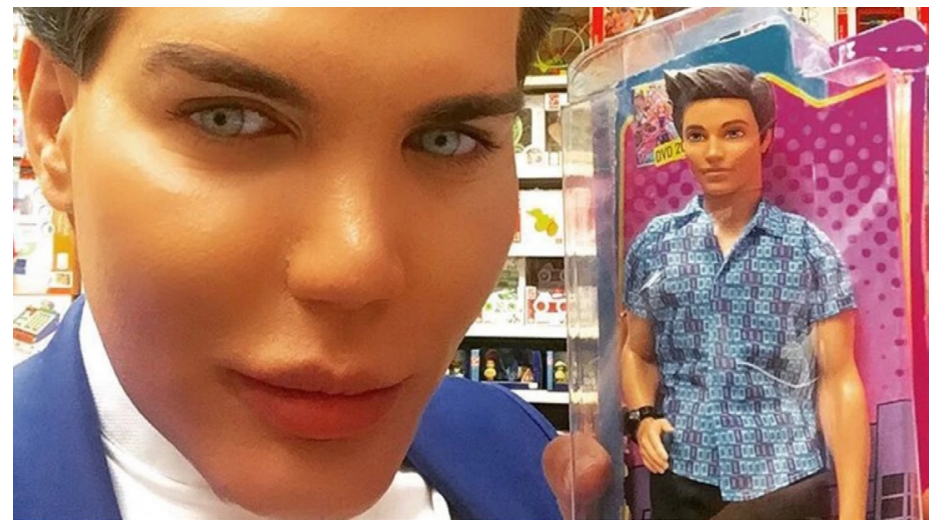

Fuente: https://www.vice.com/es_latam/article/z4knkj/quiero-verme-joven-por-siempre-rodrigo-alves-elken-humano 
La relación de los jóvenes con las redes sociales evidencia un rehacer identitario; la identidad en la red sociales mostrada a través de lo que los jóvenes comparten construye significados nuevos a partir de los significados que ya están elaborados. Su necesidad de ser incluidos en los espacios virtuales fomenta su interacción a través de lo que comparten; es un espacio simbólico de interrelación como forma de socialización. Se evidencia que entre más jóvenes son menos cuidadosos de su intimidad con respecto al material que publican en las redes sociales, como "fotografías de sus vidas" que esperan ser aprobadas por la comunidad virtual a la que pertenecen.

\section{Conclusiones}

La construcción identitaria a la que se enfrentan los adolescentes se refiere a la apropiación e interiorización de elementos dispuestos en la cultura en la que se desarrolla el sujeto. Un alto porcentaje de jóvenes tienen acceso a la red, y de ese alto porcentaje, por no decir que todos, hacen uso de redes sociales. En ella, el fenómeno YouTube supone una de las manifestaciones culturales más importantes de esta época, por la apropiación dentro del desarrollo de la identidad y el empoderamiento discursivo e ideológico mediático (que es su característica fundamental). La participación de los jóvenes en la construcción de material virtual ratifica la participación dentro de la masividad.

El escenario de interacción social de los jóvenes encuentra refugio en la Internet; esta, ha generado naturalización y espacios de intercambio encontrando respuestas a sus necesidades de comunicación. En este espacio se reproduce la ideología de los jóvenes y se constituye una nueva identidad cultural. En las redes sociales se refuerzan espacios socializadores integrando las nuevas tecnologías.

Es importante reconocer que el objeto de las nuevas tecnologías debe referirse a mejorar cada uno de los componentes de la vida social. 
En nuestro caso particular, la vida educativa, se debe considerar que a veces la escuela se piensa por fuera de la realidad contemporánea y vive sumida en un ambiente anticuado. La escuela debe aprovechar cada uno de los elementos que surgen en la sociedad y adaptarlos a su núcleo, resignificarlos para encontrar allí nuevos modelos y métodos de aprendizaje. Utilizar estos elementos en la docencia es navegar en el medio natural de nuestros alumnos mediante la innovación que, en últimas, mejora la calidad educativa, despertando la capacidad creativa de los jóvenes con un lenguaje que es el suyo y que la escuela está en la obligación de entender.

A la escuela le corresponde repensar el mundo juvenil, y participar de este apropiando su lenguaje y sus formas de participación. Debe conocer el sistema en el cual se movilizan para crear de esta manera nuevos espacios de significación profunda y coherente con el momento vertiginoso de la sociedad. De esta manera la tecnología no será en sentido negativo una herramienta vacía de contenido sino que, al contrario, se puede convertir en un mecanismo para la verdadera transformación y desarrollo social(González Gil et al.).

\section{Referencias bibliográficas}

Centro Nacional de Consultoría. (2018). Estudio de transformación y apropiación digital. Recuperado de http://hsbnoticias.com/ noticias/ciencia/tecnolog\%C3\%ADa/centro-nacional-de-consultoriarevela-estudio-de-apropiacion-375769centronacionaldeconsultoria. com/?p=usa-cialis

Congreso de Colombia. (1 de septiembre de 2014). Ley 1732. Por la cual se establece la cátedra de paz en todas las instituciones del país. Diario Oficial: 49 261. Recuperado de http://www.somoscapazes.org/ resources/PDFs/LEY\%201732\%20CÁTEDRA\%20DE\%20PAZ.PDF

Dawkins, R. (1993). El gen egoísta: las bases biológicas de nuestra conducta. Barcelona: Salvat. 
Domínguez, R. (2010). De los cuerpos torturados a los cuerpos virtuales. Trilogía: Ciencia, Tecnología, Sociedad, 2(3), 57-68.

Dueñas, J. (2018). Así usan Internet los niños y adolescentes colombianos. En: Colombia digital. Recuperado de https://www.enter.co/culturadigital/colombia-digital/internet-ninos-y-jovenes-colombianos/

Foucault, M. (2001). Vigilar y castigar: nacimiento de la prisión. Buenos Aires: Siglo XXI.

Jara, J. (1998). Nietzsche, un pensador póstumo: el cuerpo como centro de gravedad. Valparaíso: Universidad de Valparaíso.

Gallo, L. (2017). Una didáctica performativa para educar desde el cuerpo. Revista Brasileira de Ciências do Esporte, 39(2), 199-205.

González Gil, E., Aparicio Gómez, O. Y., Ostos Ortiz, O. L., Barajas Frutos, M., Alcaraz Domínguez, S., Rodríguez Illera, J. L., Pons Seguí, L. Innovación educativa y gestión del conocimiento.

Le Breton, D. (2002). Antropología del cuerpo y modernidad. Buenos Aires: Nueva Visión.

Lipovetsky, G. (1986). La era del vacío: ensayos sobre el individualismo contemporáneo. Barcelona: Anagrama.

Martín-Barbero, J. (1987). De los medios a las mediaciones: comunicación, cultura y hegemonía. Ciudad de México: Gili.

McLuhan, M. y Powers, B. (1991). La aldea global: transformaciones en la vida y los medios de comunicación mundiales en el siglo XXI. Barcelona: Gedisa.

O'Halloran, K. (2012). Análisis del discurso multimodal. Revista Latinoamericana de Estudios del Discurso. Asociación Latinoamericana de Estudios del Discurso (ALED), 12(1), 75-97. Recuperado de https:// raled.comunidadaled.org/index.php/raled/article/view/78/80 
Pardo, N. (2008a). ¿Qué nos dicen ? ¿Qué vemos ? ¿Qué es... pobreza? Análisis crítico de los medios. Bogotá: Universidad Nacional de Colombia - Instituto de Estudios en Comunicación y Cultura (IECO). Recuperado de http://bdigital.unal.edu.co/10251/

Pardo, N. (2008b). El discurso multimodal en YouTube. Revista Latinoamericana de Estudios del Discurso. Asociación Latinoamericana de Estudios del Discurso (ALED), 8(1), 77-107. Recuperado de https:// raled.comunidadaled.org/index.php/raled/article/view/120/122

Pérez, F. (2018). Políticas educativas en Colombia: en busca de la calidad. Actualidades Pedagógicas, 71, 193-213. Recuperado de https://ciencia. lasalle.edu.co/cgi/viewcontent.cgi?article=1344\&context=ap

Pérez, G., Aguilar, A. y Guillermo, M. (2004). El meme en internet. Usos sociales, reinterpretación y significados a partir de Harlem Shake. Argumentos, 27(75), 79-100. Recuperado de http://www.scielo.org.mx/ pdf/argu/v27n75/v27n75a5.pdf 